\title{
Summary of Research on Occupational Health Psychology of Social Workers
}

\author{
Xinying Chen \\ School of Public Administration \\ Guangdong University of Foreign Studies \\ Guangzhou, China. \\ Email: chenxy5171@163.com \\ China
}

\section{ABSTRACT}

With the cultivation of the government, the team of social workers continues to grow. The occupational mental health status of social workers has been paid more and more attention. Based on screening and combing the existing literature on occupational health psychology of social workers in China, this paper summarizes and reviews the research on psychological stress, anxiety and depression, and job burnout of social workers, extracts solutions and strategies from the existing research results, and hopes to be helpful to the construction and development of local social work talent team.

\section{Keywords: social worker; occupational health psychology; job burnout}

\section{Introduction}

Since the reform and open to the outside world, with the continuous development of China's society and the improvement of economic level, there have also been a large number of social problems. As the transfer system of social welfare, social work can meet the needs of different people in service and help service objects to solve problems, which is conducive to promote social equity and pursue positive changes in society. Social workers are an integral part of helping groups, and their role has been paid more and more attention by the government and the public. To promote the development of social work, the national government has issued relevant policies and regulations.

In 2006, the government released a document called Decision on Building a Socialist Harmonious Society, which proposes to build a huge team of the social worker. ${ }^{1}$ In 2010 , in the policy document, national long-term talent development program (2010-2020), the government stressed the need to focus on fostering a team of social workers. ${ }^{2}$ This document proposed a development goal to cultivate 200,000 social workers by 2015 and 3 million social workers by 2020 . Policy support has increased the total number of social workers increasing. As of 2019, the statistics of the Ministry of Civil Affairs show that the total number of social workers in the country has reached 543,000 .

Social workers refer to practitioners who agree and follow social work value guidelines and use social work methods to engage in professional social services (Wang, 2004). The particularity of the service object and the professional characteristics of social workers determine that they have to encounter negative things and become a vulnerable crowd of negative emotions. If these negative effects cannot get timely and effective relief, it will be detrimental to the mental health of social workers and even lead to resignation. Therefore, the mental health of social workers has gradually been concerned about. To understand the research situation of social workers' occupational mental health, this paper attempts to sort out and comment on the existing research results, hoping to help cultivate the team of social workers.

2. Research on the occupational health psychology of social workers

The research articles on the occupational health psychology of social workers in China are mainly divided into the following aspects: psychological stress, anxiety and depression, job burnout.

\subsection{Research on Psychological Pressure of Social Workers}

The first is the influencing factors of social workers' psychological pressure. Social workers' psychological stress comes from service objects, work context, mode, processes, assessment and risks, ethics, and position promotion (Wang, 2012). In addition, the social environment, institutional management, work, and ability of social workers have also impacted the psychological pressure (Wu, 2018).

The psychological pressure of social workers can be dealt with in the following ways. To begin with, social work institutions optimize members of the social work team, cultivate professional social workers in different services areas (Wang,2012). Formulate work incentive mechanisms, optimize institutional management and operation mechanism, carry out mental health training for social workers and improve supervision levels (Wu, 2018). In addition, the industry of social work ought to increase publicity to improve social recognition (Wang, 2012; Wu, 2018) and establish a platform to exchange ( $\mathrm{Wu}, 2018)$. What's more, the institutions and social workers work together to improve the ability of professional and self-mental health adjustment of social workers (Wu, 2018). 


\author{
E-ISSN: 2469-6501 \\ VOL: 7, ISSUE: 8 \\ August/2021 \\ DOI: http://dx.doi.org/10.33642/ijbass.v7n8p8 \\ https://creativecommons.org/licenses/by/4.0/
}

\subsection{Research on the anxiety and depression of social workers}

In psychology, anxiety refers to a lasting and negative psychological response caused by an individual's premonition of fuzzy and uncertain external dangerous stimuli, but unable to take effective methods to avoid them (Wu, 2012). Depression is a state of continuous depression, accompanied by anxiety, pessimism, disappointment, self-blame, and physical discomfort (You, Yu, Liang, 2011). Anxiety and depression often appear together.

Yuan (2012) investigated 105 social workers in Shanghai and divided them into correctional social workers, anti-drug social workers, and juvenile affairs social workers. According to the data, compared with the other two types of social workers, juvenile affairs social workers generally have anxiety and depression and are more worried about work stress, health, career prospect, and income. When social workers serve teenagers with psychological problems, it is easy for them to have anxious emotions, due to the particularity of teenagers.

$\mathrm{Wu}$ (2012) conducted a study on social workers in Nanjing and found that social workers who got a degree in high school education and below were more likely to get higher anxiety scores. Those without vocational qualification certificates are more likely to feel anxious. Among the surveyed, the depression level of female social workers is higher, while that of social workers with master's degrees or above was the most serious. The scholar proposed to solve social workers' mental health issues by the following methods: increase their salary, improve the management of social work organization and the supervision mechanism, and enhance the communication and support of their family and colleagues (Wu, 2012).

There are few studies on anxiety and depression of social workers in China, and more scholars pay attention to job burnout.

\section{Research on Job Burnout of social workers}

\subsection{Definition and characteristics of job burnout}

Among the studies on job burnout, the theory of Maslach and the theory of Pinas and Caffrey are the most representative. Most Chinese scholars use the definition of the theory of Maslach for reference. Job burnout is a state of physical and mental fatigue because the person cannot effectively relieve work pressure or properly deal with setbacks in work (Ka, Long, 2003; Jiang, 2006). Shen (2008) concluded that job burnout has the following characteristics. (1) Physical and emotional exhaustion. (2) Social behavior disorders, especially alienating service objects. (3) Psychological damage, especially point to self-intense. (4) A sense of organizational invalidation. (5) Job burnout consists of three dimensions: emotional exhaustion, depersonalization, and low personal accomplishment.

\subsection{Research object of job burnout of social workers}

Chen Wen (2008) studied social workers born between 1980 and 1989. Shen (2011) investigated 118 social workers in Shanghai Youth offices to analyze their job burnout and the level of organizational commitment. Chen (2014) surveyed 294 social workers in Guangzhou. Zhang (2014) selected 100 social workers from Guangzhou, Shenzhen, Dongguan, and Wuhan as the research object to explore the impact of social support and social environment on job burnout. Based on gender theory, Xu (2018) interviewed 13 social workers with qualitative research methods.

From the research, domestic scholars mostly study the social workers of an institution and a certain area. More studies are using quantitative research methods.

\subsection{The performance of social worker's job burnout}

Most of the research conclusions of job burnout can be summarized as emotional exhaustion, elimination of personality, and low sense of self-achievement. According to the survey of Zhang (2014), emotional exhaustion is the most serious, followed by personal achievement. In the measurement of the "remove personality" option, the score performs best. In addition, the performance of job burnout is analyzed from four aspects: physical exhaustion, mental exhaustion, emotional exhaustion, and behavioral disorder (Lan, 2013).

\subsection{Influencing factors of job burnout of social workers}

There are different ideas on the analysis of the influencing factors of social workers' job burnout. Chen (2008) pointed out that the impact factor is social work practice situation, organizational situation, and social context. Other scholars believe that the work, clients, social workers (Lan, 2013; Wang, Zhang, 2018), and institutional management (Lan, 2013) also affect the burnout level of social workers. Shen (2008) summarizes domestic and international research and point out that three aspects of the impact on the occupational burnout of social workers: work factor, service object factor, and social workers factor. This research conclusion was recognized by many scholars. Based on the viewpoint of Shen, this paper adds demographic factors to summarize the influencing factors of social workers' job burnout.

\subsubsection{Demography Variable}

Scholars analyze the correlation between demographic variables and career burnout. Li (2014) believes that marital status is an important factor affecting social worker burnout. The level of depersonalization of married social workers is higher than that of unmarried social workers (Li, 2014). Shen (2008) found that there was no significant relationship between education, professional background, professional certificate, length of employment, and job burnout.

Scholars have different views on the impact of gender variables on job burnout. One view is that there is no correlation between gender and job burnout (Shen, 2008). Gender is not a variable affecting social workers' job burnout. 


\title{
International Journal of Business and Applied Social Science (IJBASS)
}

\author{
E-ISSN: 2469-6501 \\ VOL: 7, ISSUE: 8 \\ August/2021 \\ DOI: http://dx.doi.org/10.33642/ijbass.v7n8p8 \\ (c) (i) \\ https://creativecommons.org/licenses/by/4.0/
}

There is no significant difference between male and female social workers in job satisfaction (Peng, 2012).

Another point of view believes that the gender factor is an influencing factor in occupational burnout. Lin and Zhang (2015) believe that the job burnout level of female social workers is lower than that of male social workers because female social workers play a similar role in both work and family situations. Women's emotional expression in the family is more like a hygiene factor. The boundary integration between family and work enables female social workers to promote both life and work skills, helping to reduce job burnout. Male social workers are more likely to bear the dual pressure of male social role expectation and feminist work role expectation (Lin and Zhang, 2015). Lack of emotional catharsis and greater life pressure make male social workers more prone to emotional exhaustion (Sun, 2015).

\subsubsection{Work factor}

Social workers are generally in a stable working environment, thus are inevitably affected by work factors. In organizational situations, the professionalism of organizational leaders and the nature and working environment of the organization will affect the job burnout of social workers (Chen, 2008). Wang, Zhang (2018) divided work factors into three parts: social workers' work, work content, work environment (Chen Wen, 2008). In terms of job content and workload, a large number of non-professional work will lead to a social worker role ambiguity ( $\mathrm{Lu}, 2016)$. The more workload, the more difficult work, and the more serious emotional exhaustion, the more serious job burnout will be (Zhao, 2017). Moreover, some scholars pointed out that the sense of institutional belonging and the support of colleagues and friends can significantly affect the job burnout of social workers, and the degree of influence increases in turn (Zhang, Zheng, 2014).

\subsubsection{Service object factor}

As a person who receives service and gives feedback, the service object will also have an impact on social workers. There are several reasons for the impact of job burnout on social workers. First, the severity of the service object problem. Second, the length of interaction between social workers and service objects. Third, social workers' satisfaction with the service objects (Zhang, Wu, et al., 2010). Fourth, the complexity of service objects. Finally, the bad habits of service objects (Chen, 2008).

\subsubsection{Social worker factor}

Social workers' factors will affect the level of job burnout. Firstly, social workers are insufficient in personal professional ability (Yin, 2020). Professional competence not only affects the service process and service results, but also affects the social workers who provide services. Secondly, social workers set limits on themselves (Chen, 2008). Thirdly, social workers are unclear with their career plan (Liu, 2013). The lack of clear goals in work for a long time will accelerate the dissipation of social workers' work enthusiasm.

\subsubsection{Social factors}

Low social identity, imperfect social support system and difficult establishment in the professional authority of social work cause job burnout of social workers (Chen, 2008). Social support has a great impact on social workers. It is the material and spiritual help and support provided by all parties in the society to individuals. Zhao (2017) found that the greater social support for social workers, the lower level of job burnout.

\subsection{Coping methods of social workers' Job Burnout 3.5.1 Measures of social workers}

In the face of job burnout, social workers must take action to deal with it. First of all, social workers should strengthen identity of their careers, perceive themselves regularly and care about themselves appropriately (Chen, 2008). In addition, learn how to regulate emotions and reduce stress (Shen, 2008). When encountering work difficulties and negative emotions, social workers take the initiative to adjust themselves (Chen, 2018). Of course, strengthen the communication skills with service objects and colleagues (Shen, 2008). The support of colleagues and friends has a significant impact on the level of job burnout of social workers (Zhang, Zheng, et al., 2014). Finally, social workers should learn to distinguish the boundaries of work and life, reduce the troubles brought by work (Chen, 2018).

\subsubsection{Measures of social work organization}

Organizational environment has a direct impact on the career burnout of social workers (Shen, 2008; Zhang, Zheng, et al., 2014). First, social work institutions should be set out the requirements and responsibilities of the different social jobs (Shen, Liu, 2011). Help social workers carry out career management and create conditions to promote the development of social workers. Second, the quality of institutional management personnel has an impact on the atmosphere of the organization. Chen (2008) proposed to improve the quality of the leader. Coordinate the relationship between leaders and social workers in the work. Provide opportunities for social workers to participate in institutional management and decision-making.

Third, institutions should build a platform for social workers to communicate. Effective internal communication will reduce the job burnout. For example, establish a workshop to reduce stress of social workers, let them have the opportunity to share their experiences and sentiments (Chen, 2008). Fourth, open up the professional promotion channel for social workers. To meet the different preferences of professional social workers, social work agencies are supposed to provide two different career paths between the management positions and technical positions (Shen, Liu, 2011).

Fifth, establish and improve the incentive system. Incentives include material rewards and spiritual support. Social work institutions ought to establish a reasonable salary system and balance the relationship between social workers' income and work input. Increase spiritual encouragement, 


\title{
International Journal of Business and Applied Social Science (IJBASS)
}

\author{
E-ISSN: 2469-6501 \\ VOL: 7, ISSUE: 8 \\ August/2021 \\ DOI: http://dx.doi.org/10.33642/ijbass.v7n8p8 \\ (c) (7) \\ https://creativecommons.org/licenses/by/4.0/
}

providing a chance to deepen progress (Shen, 2007). Increasing the investment of social workers' resources will reduce the degree of job burnout (Lin, Zhang, 2015).

Finally, the sense of organizational support is one of the important sources of work motivation, and social work institutions are supposed to provide support for social workers (Chen, Shang, 2014). It can not only increase the work motivation of social workers, but also increase their sense of belonging to the organization. Zhang and Zheng (2014) surveyed 100 social workers. There is a significant difference between social workers' sense of belonging to institutions and the degree of job burnout, and there is a negative correlation between them. Therefore, social work institutions can help social workers reduce job burnout by increasing social support.

\subsubsection{Measures of Government}

The main funds and resources of China's social work institutions come from the government. The policy support and coordination of government departments is a important social support system for social work (Chen, 2008). Government departments coordinate the cooperative relationship and roles between social workers and various systems to avoid conflicts. The government needs to assist all departments of district and county to clarify how to manage social work institutions (Shen, Liu,2011). Accelerate legislation and issue standardized regulations on the management of social work industry (Chen, 2018).

Unreasonable salary is easy to cause dissatisfaction of social workers. Generally, the salary level is negatively correlated with the probability of job burnout. The lower level of salary, the higher level of the probability of job burnout (Shen, Liu, 2011). Therefore, the government should formulate a wage standard policy. Help the social work industry establish a reasonable salary system and improve incentive policies. In addition, enhance the public's recognition of social work (Zhao, 2017).

\subsubsection{Measures of Media}

The publicity of social work culture should be strengthened (Chen, 2008). Give full play to the publicity function of the media. It actively publicizes and reports social work and increases the public's understanding and recognition of social work (Shen, Liu, 2011). However, it should also be noted that the media should publicize the professionalism of social work and should not exaggerate the ability of social workers. Reporting cannot shape social workers into a "omnipotent good person" to avoid aggravating social workers' moral burden (Shen, 2008).

\section{Conclusions}

By summarizing the existing domestic research literature, it is found that more and more scholars pay attention to the mental health problems of social workers. On the one hand, scholars have made a detailed study on the status, performance, influencing factors and coping strategies of social workers' job burnout. However, the conclusion of coping methods is lack of innovation. On the other hand, there are few studies on social workers' psychological stress, anxiety and depression, alternative trauma, compassion fatigue and other mental health, which need to be supplemented.

\section{References}

Chen, R. L. (2018). Study on the Professional Burnout of First - line Social Workers from the Perspective of Emotional Labor, M.A. Thesis. Capital

Chen, W. (2008). Difficulties in field pressure and "80-after" social workers. Theoretical Monthly, 000(005), 185-187 (In Chinese).

Chen, W., Shang, H. R., Zeng, K. \& Liu, G. Y. (2014). The mediating role of social workers' psychological capital between organizational support and job burnout. Chinese Journal of health psychology, 000(007), 1063-1064 (In Chinese).

Gao, J. G. (2013). Research on male social workers' professional confusion from the perspective of gender role, M.A. Thesis. Nanjing University (In Chinese).

Ka, R., Long, L. R. (2003). Theoretical Research and Progress in Work Burnout. Chinese Journal of Clinical Psychology, 11(4), 317-320 (In Chinese).

Lan, Y. C. (2013). Study on the Countermeasures of social workers' Job Burnout. Journal of Qinghai Normal University (Philosophy and Social Science Edition), 35(003), 46-48 (In Chinese).

Lin, C. Y., Zhang, X. J. (2015). Social Worker Remuneration and Work Burnout Investigation - Taking Guangzhou as an Example. City Issues, 000(002), 78-86 (In Chinese).

Li, H. (2014). Research on Job Burnout of practical social workers, M.A. Thesis. Central China Normal University (In Chinese).

Li, J. J. (2014). Job burnout assessment, factor identification and intervention strategies of social workers -- a survey of 250 social workers in Beijing, Shanghai, Guangzhou, Shenzhen, Dongguan, Wuhan and Chongqing, M.A. Thesis. Central China Normal University (In Chinese).

Liu, W. J. (2015). Job burnout of front-line social workers in Shenzhen and Its Solutions, M.A. Thesis. Nanjing University (In Chinese). 


\author{
E-ISSN: 2469-6501 \\ VOL: 7, ISSUE: 8 \\ August/2021 \\ DOI: http://dx.doi.org/10.33642/ijbass.v7n8p8 \\ (c) (i) \\ https://creativecommons.org/licenses/by/4.0/
}

Lu, F. J. (2016). Investigation and Analysis of Social Workers' Professional Burnout - Taking Shanghai as an Example. Journal of Guangdong University of Technology (Social Science Edition), 016(002), 40-47 (In Chinese).

Miao, Q. Q. (2012). Research on the supervision mechanism of social workers' job burnout -- a case study of Suzhou, M.A. Thesis. Suzhou University (In Chinese).

Peng, J. (2012). Social work intervention of social workers' job burnout, M.A. Thesis. Zhengzhou University (In Chinese).

Ren, Y. X. (2013). Investigation on Job Burnout of social workers -- a case study of social workers in Shenzhen. Journal of Beijing University of Science and Technology (Social Science Edition) (02), 44-49 (In Chinese).

Shen, L. (2008). Social worker burnout: international studies and enlightenment. Youth Journal (2), 33-35 (In Chinese).

Shen, L., Liu, L. \& Liu, B. Z. (2011). Social Workers' Professional Burnout and Organizational Commitment - Taking Shanghai Youth Affairs Social Worker as an Example. Youth Exploration (03), 48-53 (In Chinese).

Shi, Y., Shi, T. Q. (2013). Research on Job Burnout of social workers from the perspective of social support. Social Sciences (New Theory Edition) (01), 150-152 (In Chinese).

Wang, C. M., Zhang, X., Ye, C. P., Chen, W. L. \&Li, M. L. (2020). Analysis of mental health status of mental health social workers in Longgang District, Shenzhen. Occupation and health, v.36 (19), 79-82 (In Chinese).

Wang, M. Y., \& Zhang, S. S. (2018). From Western Concept to Local Research: Review of the Study of the Professional Burnout of Chinese Social Workers. Journal of Aba Teachers College, 035(004), 102-108 (In Chinese).

Wang, X. L. (2012). Talking about the psychological pressure of youth social workers. Social work (7), 45-47 (In Chinese).

Wu, H. (2015). Measurement and Research of Anxiety, Depression of Young Social Workers in Social Working Organizations, M.A. Thesis. Nanjing University (In Chinese).

Wu, H. (2018). Research on the Psychological Phambits of Social Workers and Countermeasures, M.A. Thesis. Northwestern University (In Chinese).

Wang, S. B. (2006). Introduction to social work. (Version 2). Higher Education Press. PP21-22 (In Chinese).

$\mathrm{Xu}$, S. S. (2018). Research on the Status of Social Workers' Professional Burnout under the Perspective of Social Gender. Social Work, No.275 (02), 65-75+113 (In Chinese).

Yin, M. M. (2020). Research on Job Burnout of social workers, M.A. Thesis. Anhui University (In Chinese).

You, Y. H., Yu, S. P. \& Liang, B. (2011). Trial and evaluation of Beck Depression Questionnaire among teachers in disaster areas. Journal of Sichuan Normal University (Natural Science Edition) (2), 439-442 (In Chinese).

Yuan, W. J., Ren. Q. H., \& Wang, Z. W. (2014). Investigation and Analysis on mental health status of social workers in a district of Shanghai. Chinese Journal of Drug Abuse Prevention and Treatment (4), 187-190 (In Chinese).

Zhang, D. W., Zheng, Y. J. \& Li, J. J. (2014). Occupational social environment, social support and social worker exhaustion based on a survey of Guangzhou, Dongguan, Shenzhen, Wuhan 100 full-time social worker. Zhongzhou Journal (02), 79-84 (In Chinese).

Zhao, N. (2017). Research on the Affecting Factors and Countermeasures of Professional Burnout of Youth Affairs Social Workers, M.A. Thesis. China Youth Political College (In Chinese).

Zhang, Q., Wu, B., Xie, M. Z. \& Chen, S. (2010). Review and Prospect of research on occupational health psychology of social workers. Modern business, 000(015), 273-274 (In Chinese). 